\title{
FOLLOWUP STUDY OF OCULAR CHANGES IN TOXIC GAS EXPOSED POPULATION AT BHOPAL
}

\author{
Samreen Arif1, Sanjay Shrivastava²
}

${ }^{1}$ Senior Medical Officer, Department of Ophthalmology, BMHRC.

2Professor, Department of Ophthalmology, Regional Institute of Ophthalmology, Bhopal.

\section{ABSTRACT}

\section{BACKGROUND}

Bhopal gas tragedy was one of the worst and biggest industrial disaster of the world and it was feared that toxic gas inhalation (Methyl isocyanate) and exposure toxicity might lead to progressive multisystem morbidities. This demanded constant surveillance, intensive research into population based long-term epidemiological studies and development of comprehensive care system to provide relief to sick and suffering.

Aim of this study is to estimate and evaluate delayed ocular effects and progression of already existing ocular morbidity in toxic gas exposed population.

\section{MATERIALS AND METHODS}

Prospective cohort study.

\section{RESULTS}

Most common age group was 21 - 50 years. DOV was most prominent symptom and lenticular opacity most common finding. There was reduction in incidence of burning sensation, redness, discharge, conjunctival xerosis, corneal opacity, chronic irritative conjunctivitis and trachoma as compared to previous studies. Increased incidence of pterygium, pinguecula, lenticular opacity, pseudophakia and fundus changes as compared to previous studies. Incidence of corneal opacity was higher than national incidence.

\section{CONCLUSION}

Increased incidence of cataract and ARMD was due to more number of older individuals in study. Decreased incidence of irritative conjunctivitis, infectious diseases, conjunctival xerosis and increased incidence of hypertensive retinopathy, diabetic retinopathy and pseudophakia as compared to previous studies can be attributed to better sanitation and living condition, increased awareness of individuals, increased life expectancy of individuals with long duration of systemic diseases, better and easily approachable health services with free supply of medicines to gas victims. Higher incidence of corneal opacity was due to more inmates in study involved in outdoor activities.

\section{KEYWORDS}

Methyl Isocyanate, Diminution of Vision, Corneal Opacity, Lenticular Opacity.

HOW TO CITE THIS ARTICLE: Arif S, Shrivastava S. Followup study of ocular changes in toxic gas exposed population at Bhopal. J. Evolution Med. Dent. Sci. 2016;5(92):6842-6845, DOI: 10.14260/jemds/2016/1547

\section{BACKGROUND}

On the night intervening $2^{\text {nd }}$ and $3^{\text {rd }}$ December 1984, there was massive release of approximately 40 tons of highly toxic gas and its reactive products escaped in gaseous form from the pesticide plant at Bhopal, owned by American Multinational Company Union Carbide Corporation.[1] The gas cloud was composed mainly of Methyl Isocyanate (MIC), apart from it other gases such as phosgene, hydrogen cyanide, carbon monoxide, hydrogen chloride, nitrous oxide, monomethylamine and carbon dioxide either produced in the storage tank or in the atmosphere was present. All these except carbon dioxide were toxic at levels below 500 ppm. ${ }^{[2]}$

MIC is clear, colourless, lacrymatory, sharp smelling organic compound which is soluble in water. It is highly toxic and irritating material, which is hazardous to human

Financial or Other, Competing Interest: None.

Submission 09-10-2016, Peer Review 05-11-2016,

Acceptance 11-11-2016, Published 17-11-2016.

Corresponding Author:

Dr. Samreen Arif,

Senior Medical Officer,

Department of Ophthalmology,

Bhopal Memorial Hospital \& Research Centre.

E-mail: drsamreenarif@gmail.com

DOI: $10.14260 /$ jemds/2016/1547 health.[3][4] The threshold limit value set by American Conference on Government Industrial Hygienist was $0.02 \mathrm{ppm}$. MIC can damage by inhalation, ingestion and contact in quantities as low as $0.4 \mathrm{ppm}$. MIC is potent lachrymator at 2 $4 \mathrm{ppm}$; at $21 \mathrm{ppm}$ subjects could not tolerate its presence.[5]

Union Carbide Pesticide Plant in Bhopal used to produce Sevin (Trade brand name of carbaryl) producing MIC as an intermediate.[6]

ICMR estimated that out of total 832094 population of Bhopal, 521262 suffered from inhalational and exposure toxicity, while 311642 escaped the effect of toxic gases. The first official death toll within 72 hrs. was 2259. At this the nation was shocked facing unprecedented health problems of a totally new disease as nothing was known about its pathogenesis, prognosis and treatment which demanded intensive research into population based long-term epidemiological studies.[1]

Long term followup study was done by ICMR in 2 phases on gas victims:

Phase I - March 1985 to August 1988.

Phase II - September 1988 to September 1992.

Followup study on delayed ocular effects in exposed population done by Dr. S. B. Gupta and Dr. Ahluwalia between June 2001 and November 2002 under ICMR. [7] 
Present study was carried out between March 2009 and December 2010 on persons who were randomly selected from ICMR baseline cohort registered from severely exposed areas.

Out of 521262 inmates exposed to MIC, 80021 inmates were registered for medical research; 4946 persons examined in Phase II study by ICMR. Out of these 4946 persons, 200 persons from severely exposed area were randomly selected from ICMR cohort.

\section{MATERIALS AND METHODS}

Study Design

Prospective cohort study.

\section{Duration}

March 2009 - 30th December 2010.

\section{Study Place}

Department of Ophthalmology, GMC.

200 individuals were selected by cluster random sampling from ICMR baseline cohort registered from severely exposed areas for long-term epidemiological study.

These subjects were identified with the help of ICMR field worker by door to door survey and their preliminary examination was done at field with the help of torch, loupe and ophthalmoscope by the doctor. All subjects were referred to Department of Ophthalmology, GMC, Bhopal where detailed examination was done which includes refraction, slit lamp examination, fundus examination under mydriasis. In relevant subjects' tonometry, syringing, corneal sensation, Schirmer test, TBUT and fluorescein stain was done. After collection of data, analysis of data was done. Test of significance was applied to selective parameters by chi square test using standard method for statistical analysis.

\section{RESULTS}

In present study, $43.5 \%$ were males and $56.5 \%$ were females. Maximum number of inmates (41\%) were in age group 21 - 40 yrs. and 41 - 60 yrs., each followed by $16.5 \%$ in 61 - 80 yrs. and $1.5 \%$ were $>80$ yrs. old.

\section{Distribution according to Ocular Complaints}

\begin{tabular}{|c|c|c|c|}
\hline $\begin{array}{l}\text { Sl. } \\
\text { No. }\end{array}$ & Ocular Complaints & $\begin{array}{l}\text { No. of } \\
\text { Cases }\end{array}$ & Percentage \\
\hline 1 & Burning Sensation & 24 & 12 \\
\hline 2 & $\begin{array}{c}\text { Diminution of } \\
\text { Vision }\end{array}$ & 115 & 57.5 \\
\hline 3 & Watering & 17 & 8.5 \\
\hline 4 & Itching & 24 & 12 \\
\hline 5 & Eyestrain & 27 & 13.5 \\
\hline 6 & Redness & 33 & 1.65 \\
\hline 7 & F. B. Sensations & 10 & 5 \\
\hline 8 & Dryness & 1 & 0.5 \\
\hline 9 & Swelling of Eyes & 2 & 1 \\
\hline 10 & Headache & 18 & 9 \\
\hline 11 & Discharge & 19 & 9.5 \\
\hline 12 & Eye Stickiness & 4 & 2 \\
\hline 14 & Deviation & 1 & 0.5 \\
\hline 15 & No Complaints & 37 & 18.5 \\
\hline
\end{tabular}

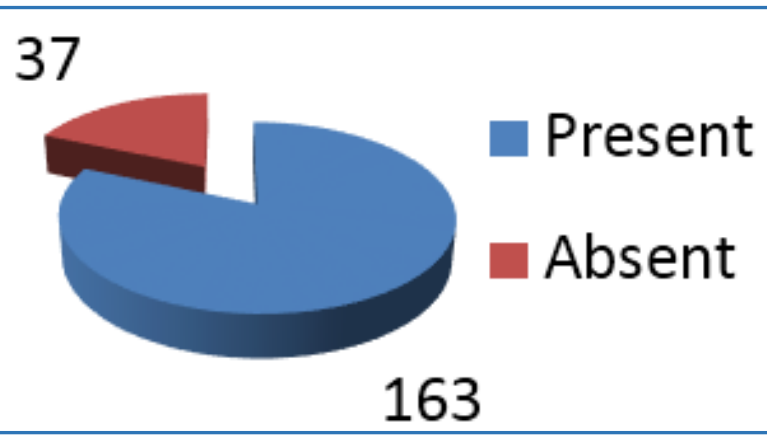

Figure 1. Distribution according to Ocular Complaints

DOV was the most prominent symptom, $57.5 \%$ followed by eye strain and burning sensation; $18.5 \%$ does not have any complaint.

\begin{tabular}{|c|l|c|c|}
\hline $\begin{array}{c}\text { Sl. } \\
\text { No. }\end{array}$ & \multicolumn{1}{|c|}{ Ocular Findings } & $\begin{array}{c}\text { No. of } \\
\text { Cases }\end{array}$ & Percentage \\
\hline 1 & Refractive Error & 65 & 30 \\
\hline 2 & Meibomianitis & 18 & 6.5 \\
\hline 3 & Senile Ectropion & 7 & 3.5 \\
\hline 4 & Blepharitis & 2 & 1 \\
\hline 5 & Blepharochalasis & 1 & 0.5 \\
\hline 6 & $\begin{array}{l}\text { Degenerative Diseases of } \\
\text { Conjunctiva }\end{array}$ & 17 & 8.5 \\
\hline 7 & Conjunctivitis & 35 & 18 \\
\hline 8 & Trachoma & 1 & 0.5 \\
\hline 9 & Corneal Opacity & 10 & 5 \\
\hline 10 & Lenticular Opacity & 76 & 38 \\
\hline 11 & Corneal Dystrophy & 2 & 1 \\
\hline 12 & Pseudophakia & 14 & 7 \\
\hline 13 & Aphakia & 1 & 0.5 \\
\hline 14 & Dry Eye & 2 & 1 \\
\hline 15 & Squint & 18 & 3 \\
\hline 16 & $\begin{array}{l}\text { Convergence } \\
\text { Insufficiency }\end{array}$ & 8 & 2 \\
\hline 17 & $\begin{array}{l}\text { Retina and Optic Nerve } \\
\text { Changes }\end{array}$ & 14 & 7.5 \\
\hline 18 & Amblyopia & 4 & 1 \\
\hline 19 & NAD & 20 & 8 \\
\hline Table 2. Distribution according to Ocular Findings \\
\hline
\end{tabular}

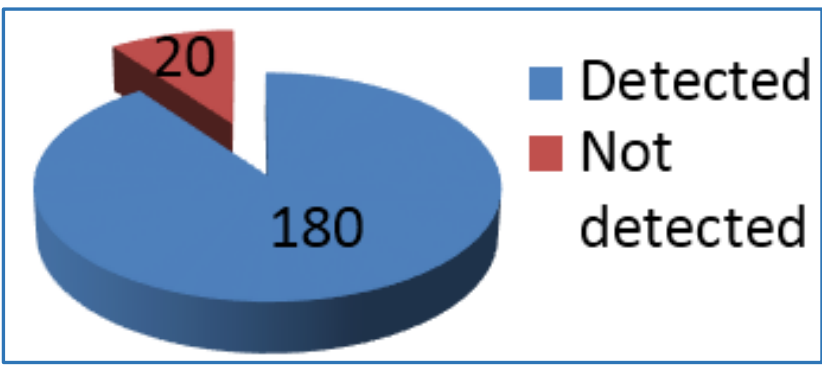

Figure 2. Distribution according to Ocular Abnormality

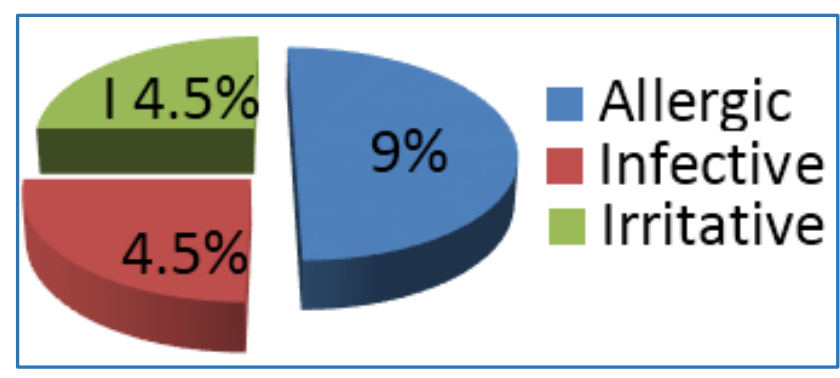

Figure 3. Distribution according to Type of Conjunctivitis 


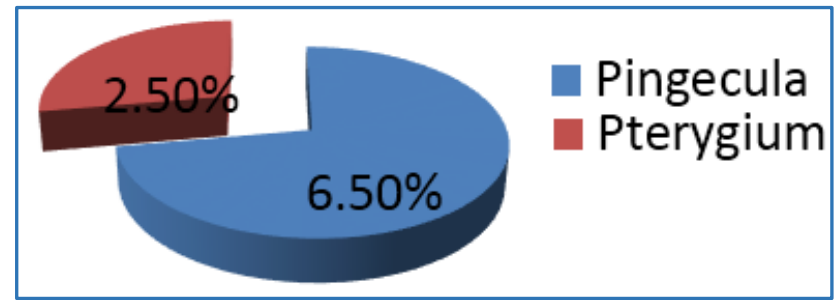

Figure 4. Distribution according to Type of Degenerative Diseases of Conjunctiva

Most common ocular finding was lenticular opacity 38\% followed by refractive error $30 \%$ and $8 \%$ were having no abnormality; $18 \%$ of individuals were having conjunctivitis (9\% allergic, $4.5 \%$ irritative and $4.5 \%$ infectious conjunctivitis); $8.5 \%$ were having degenerative diseases of conjunctiva ( $6 \%$ pinguecula and $2.5 \%$ pterygium).

\begin{tabular}{|c|c|c|c|c|c|}
\hline \multirow{2}{*}{$\begin{array}{r}\text { Sl. } \\
\text { No. }\end{array}$} & \multirow{2}{*}{ Visual Acuity } & \multicolumn{2}{|c|}{ Right Eye } & \multicolumn{2}{|c|}{ Left Eye } \\
\hline & & No. & $\%$ & No. & $\%$ \\
\hline 1 & $6 / 6-6 / 12$ & 168 & 84 & 172 & 86 \\
\hline 2 & $6 / 18-6 / 24$ & 22 & 11 & 13 & 6.5 \\
\hline 3 & $6 / 36-6 / 60$ & 8 & 4 & 11 & 5.5 \\
\hline 4 & $<6 / 60$ & 2 & 1 & 4 & 2 \\
\hline 5 & $\mathrm{HM}+\mathrm{PR}^{*}$ & - & - & - & - \\
\hline 6 & No. PL & - & - & - & - \\
\hline \multicolumn{2}{|r|}{ Total } & 200 & 100 & 200 & 100 \\
\hline \multicolumn{6}{|c|}{ ble 3. Distribution according to Visual Acuity } \\
\hline
\end{tabular}

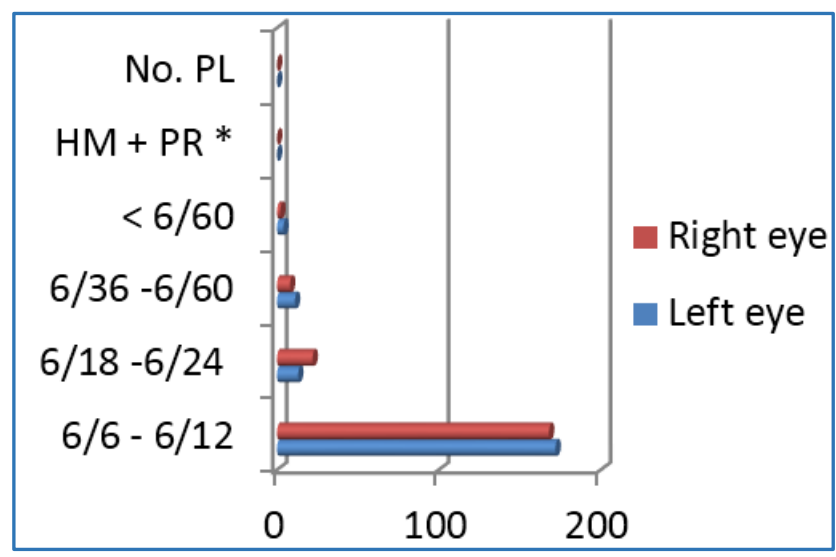

Figure 5. Distribution according to Visual Acuity

Maximum number of inmates have visual acuity in right and left eye between $6 / 6-6 / 12$. No individual was having vision $\mathrm{HM}+\mathrm{PR}+$ or no PL.

\begin{tabular}{|c|c|c|c|c|}
\hline $\begin{array}{l}\text { Sl. } \\
\text { No. }\end{array}$ & $\begin{array}{c}\text { Age } \\
\text { Groups }\end{array}$ & $\begin{array}{l}\text { Total } \\
\text { No. of } \\
\text { Cases }\end{array}$ & $\begin{array}{l}\text { No. of } \\
\text { Cases } \\
\text { with } \\
\text { Cataract }\end{array}$ & $\begin{array}{c}\text { Percentage } \\
\text { from Total No. } \\
\text { of Cases in Age } \\
\text { Group }\end{array}$ \\
\hline 1 & $0-10$ & & & \\
\hline 2 & $11-20$ & - & - & - \\
\hline 3 & $21-30$ & 30 & 1 & 3.33 \\
\hline 4 & $31-40$ & 52 & 3 & 5.76 \\
\hline 5 & $41-50$ & 51 & 17 & 33.33 \\
\hline 6 & $51-60$ & 31 & 21 & 67.74 \\
\hline 7 & $61-70$ & 26 & 24 & 93.30 \\
\hline 8 & $71-80$ & 7 & 7 & 100 \\
\hline 9 & $>80$ & 3 & 3 & 100 \\
\hline \multicolumn{2}{|c|}{ Total } & 200 & 76 & 38 \\
\hline \multicolumn{5}{|c|}{ Table 4: Age Distribution of Lenticular Opacity } \\
\hline
\end{tabular}

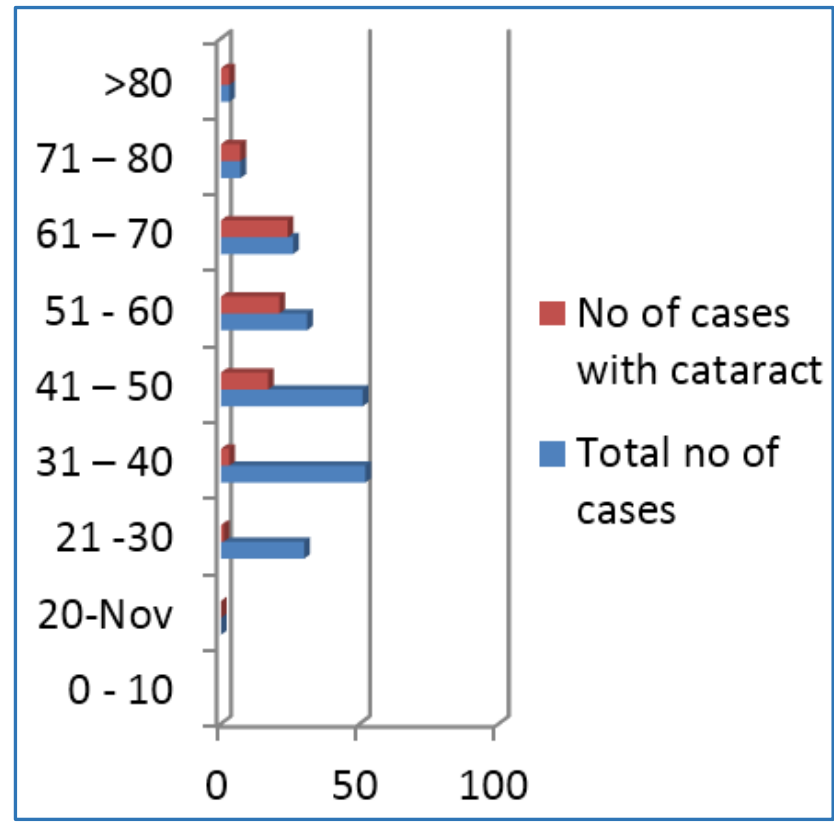

Figure 6. Age Distribution of Lenticular Opacity

109 individuals had clear lens, 76 had cataract $(13 \%$ cortical, $25.50 \%$ nuclear sclerosis, $15.50 \%$ posterior subcapsular, $2.5 \%$ mature cataract, $1 \%$ posterior polar); $100 \%$ individuals in age group $71-80 \mathrm{yrs}$. and $>80 \mathrm{yrs}$. were having cataract $67.74 \%$ in age group $51-60$ yrs. and $3.33 \%$ in age group 21 - 30 yrs.

9 individuals were having corneal opacity $(3.5 \%$ nebulomacular, $\quad 0.5 \% \quad$ maculo-leucomatous, $\quad 0.5 \%$ leucomatous). All the corneal opacities were unilateral and present in interpalpebral area except 2 individuals having bilateral corneal opacities at periphery in documented case of sclerosing keratitis and over entire cornea in documented case of granular stromal dystrophy who also showed progression of opacities.

5 individuals were having exotropia and 13 exophoria, out of which 8 individuals were having convergence insufficiency. Only 2 patients who were documented cases of rheumatoid arthritis having decreased Schirmer and TBUT reading.

Fundus abnormalities were present in 16 individuals (8\%) [ 4 hypertensive retinopathy, 2 diabetic retinopathy, 2 macular scar, 4 age related macular degeneration, 3 drusen and 1 optic atrophy].

\section{DISCUSSION AND CONCLUSION}

More number of inmates were in age group 21 - 40 and 40 - 60 yrs. and $1.5 \%$ were $>80 \mathrm{yrs}$. as contrast to study conducted in 2002, where more number of inmates were in 40 - $60 \mathrm{yrs}$. and no inmates were $>80 \mathrm{yrs}$. This might be due to increase in biological age of gas victims and increase in life expectancy due to better health facilities. ${ }^{[7]}$

Most common ocular finding was DOV in present study and also survey conducted in 2002 and Phase II study done by ICMR in contrast to study done by Anderson et al in 1984 and Dwivedi P. C. et al in 1985 reported burning sensation as the most prominent symptom.[8][9] This is due to increased incidence of patients with refractive error, cataract and patient developing presbyopia in present study. Only $12 \%$ of inmates reported burning sensation of eyes, which is significantly less 
( $\mathrm{p}<0.001$ ) as compared to study done in 1984 and 1985 due to subsidence of acute toxic effect of toxic gas exposure.

Most common ocular finding was found to be lenticular opacity (38\%) in present study followed by refractive error (30\%). Survey conducted in 2002 showed refractive error in $18 \%$, lenticular opacity in $11 \%$, trachoma in $2.4 \%$ and corneal opacity in $1.9 \%$ inmates. During Phase II study $16.2 \%$ inmates had refractive error, $15.1 \%$ corneal opacity, $13.9 \%$ trachoma and lenticular opacity $6.1 \% .{ }^{[7]}$

There was increased incidence of refractive error $(30 \%)$ and cataract (38\%) in present study as compared to Phase II study, where it was $18 \%$ and $11 \%$ respectively.[7] Increased incidence of cataract is due to increased incidence of age related cataractous changes due to increased number of inmates in older age group in present study.

There was significant reduction $(\mathrm{p}<0.001)$ in incidence of trachoma in present study $(0.5 \%)$ as compared to Phase II study (13.9\%). This can be attributed to better medical care with free supply of medicines and better sanitation in gas affected areas.[1]

No patients with conjunctival xerosis found in present study as compared to Phase I study where it was reported in gas victims and when prevalence was re-estimated after 3 - 4 yrs. (Phase II study), an increase in prevalence was observed. Absence of conjunctival xerosis in present study might be due to better nutritional status and awareness in gas victims.[1]

Maximum number of individuals in present study have visual acuity in both eyes between 6/6 - 6/12, which corresponds to similar pattern of visual acuity in survey conducted in 2002.[7]

The prevalence of chronic irritative conjunctivitis was $50.3 \%$ in Phase I study and $26.5 \%$ in Phase II study. In present study, it was $4.5 \%$.[1] Chronic conjunctivitis is one of the main chronic lesion noticed by Raizada JK and Dwivedi PC 1987. This pattern might be attributed to subsidence of toxic effect of gas in exposed population with time and better health facilities including free supply of medicines to gas victims.

The incidence of degenerative diseases (Pinguecula and pterygium) was $8.5 \%$ as compared to study done in 1987 , where it was $1.63 \%$ and $5.5 \%$ in survey done in 2002 . This might be more involvement of individuals in outdoor activities and exposure to dust and sunlight.[7]

In present study the incidence of corneal opacity was $5 \%$ as compared to survey done in 2002 , where it was $1.9 \%$ and $15.1 \%$ in Phase II study. The prevalence of corneal opacity in present study was higher than national incidence which was $0.73 \%$, which can be attributed to outdoor activities including lathe machine work and labourers. The highest incidence of corneal opacity in Phase I and Phase II study is not reflected in present study might be due to disappearance of superficial nebular opacities with time, especially in relatively younger age group.[1]

In present study no patient with nebular corneal opacity was found in comparison to survey done in 2002, where it was present in $1 \%$ inmates. This might be due to difference in method of examination in present and previous study, early diagnosis of opacity and they might have disappeared with time/proper treatment and progression of opacity to nebulomacular type.[7]
In present study, $38 \%$ of individuals had lenticular opacity as compared to previous survey done in 2002 and Phase II study which was $11 \%$ and $8.7 \%$ respectively and was also higher than the national incidence of cataract which was $14.2 \%$. This might be due to increased inmates in present study in senile age group and decreased number of young individuals in present study.[1]

In present study 13 individuals (6.5\%) were having exophoria, out which 8 individuals were having convergence insufficiency. This group mostly involves females who were students or involved more in near work like tailor, teacher, etc. In present study, fundus abnormalities were present in 16 individuals (8\%) as compared to $6.1 \%$ in Phase I study and $4 \%$ in Phase II study. In Phase I and II study, the fundus changes reported were pigmentary changes at macula. In present study, out of 22 individuals who were documented cases of hypertension and 8 diabetes mellitus 4 patients had hypertensive retinopathy and 2 patients diabetic retinopathy and these patients were having history of uncontrolled hypertension and diabetes mellitus of $>10$ yrs., 4 patients were having age related macular degeneration and all were above 50 yrs. of age. These changes might be due to long duration of systemic diseases in patients and also due to increased life expectancy of individuals with systemic diseases.[1]

\section{REFERENCES}

1. Raizada JK, Mittal PC, Ahmed H, et al. Follow up study of ocular changes in MIC/Toxic gas exposed population on long term basis. ICMR technical report on population based long term clinical studies (1985 - 1994). Health effects of toxic gas leak from the Union Carbide Methyl Isocynate plant in Bhopal. Chapter 12. 2009:147-168.

2. Eckerman. The Bhopal Saga-causes and consequences of the World's largest industrial disaster. India: Universities Press ISBN 81-371-51-7. 2004.

3. Jennifer R. At 1984-Huge Poison Gas Leak in Bhopal, India http://history1900s.about.com/od/1980s/qt/bhopal.ht $\mathrm{m}$

4. Union Carbide Corporation "Methyl Isocyanate" Product Information Publication F-41443, 1967.

5. IPCS, CEC: International chemical safety card on Methyl Isocyanate. 2003. http://www.inchem.org/documents/icsc/icsc/eics0004. htm.

6. Unger TA. Pesticide synthesis handbook. Norwish, NY: William Andrew Inc., ISBN 0815514018. 1996:67-8.

7. Gupta SB. Consolidated report on medical research: follow up study on delayed ocular effects in MIC exposed population of Bhopal. Chapter VII. 2001-2002:27-46.

8. Anderson N, Muir MK, Mehra V. Bhopal eye (letter). Lancet 1984;2:1481.

9. J Postgrad Med 1986;32:199-202. http://www. jpgmonline.com/text.asp?1986/32/4/199/5328 